\title{
Association between ABO and Rh Blood Groups and Pregnancy-induced Hypertensive Disorders
}

\author{
${ }^{1}$ Mridu Sinha, ${ }^{2}$ Sonam Maheshwari, ${ }^{3}$ Puneet Gupta
}

\begin{abstract}
Objective: To find out if there is any association between $A B O$ and Rh blood groups and pregnancy-induced hypertensive $(\mathrm{PIH})$ disorders, i.e. gestational hypertension $(\mathrm{GH})$, preeclampsia (PE) and eclampsia (E).

Materials and methods: This was a 4-year retrospective study from Jan 2010 to Jan 2014, of all admitted primigravidas with singleton deliveries diagnosed with $\mathrm{GH}, \mathrm{PE}$ or $\mathrm{E}$. Using Chisquare test and multinomial logistic regression, association and relative risk with $95 \%$ confidence interval of pregnancyinduced hypertensive disorders with different blood groups were observed respectively.
\end{abstract}

Results: It was observed that pregnancy-induced hypertensive disorders are significantly associated with blood groups ( $p=$ 0.017). Primigravidas with $A B$ blood group have about five times higher risk of developing eclampsia and blood group A has $50 \%$ more chance of developing pre-eclampsia when compared to blood group $\mathrm{O}$. However, no association was found between $\mathrm{PIH}$ and RhD group.

Conclusion: Our findings in Indian population are consistent with other studies done so far. This may help us to improve the understanding of etiology of gestational hypertensive disorders, which will further predict the prognosis and decide the management guidelines. Thus, attention should be given to primigravidas with $\mathrm{AB}$ blood group to prevent complications of $\mathrm{PIH}$ and improve the prognosis.

Keywords: ABO blood groups, Eclampsia, Gestational hypertension, PIH, Pre-eclampsia.

How to cite this article: Sinha M, Maheshwari S, Gupta P. Association between $\mathrm{ABO}$ and $\mathrm{Rh}$ Blood Groups and Pregnancy-induced Hypertensive Disorders. J South Asian Feder Obst Gynae 2016;8(1):8-12.

Source of support: Nil

Conflict of interest: None

Date of received: 5 January 2016

${ }^{1}$ Assistant Professor, ${ }^{2}$ Lecturer, ${ }^{3}$ Assistant Statistical Officer

${ }^{1}$ Department of Obstetrics and Gynecology, Shri Ram Murti Smarak Institute of Medical Sciences, Bareilly, Uttar Pradesh India

${ }^{2}$ Department of Preventive and Social Medicine, Shri Ram Murti Smarak Institute of Medical Sciences, Bareilly, Uttar Pradesh India

${ }^{3}$ Department of Economics and Statistics Office, Vikas Bhawan Bareilly, Uttar Pradesh, India

Corresponding Author: Mridu Sinha, Assistant Professor Department of Obstetrics and Gynecology, Shri Ram Murti Smarak Institute of Medical Sciences, Bareilly, Uttar Pradesh India, Phone: 09897608050, e-mail: sinhamridu72@gmail.com
Date of acceptance: 8 February 2016

Date of publication: March 2016

\section{INTRODUCTION}

Hypertensive disorders of pregnancy are the most common medical problem encountered during pregnancy and are the leading cause of maternal as well as perinatal morbidity and mortality worldwide. These can be in the form of gestational hypertension $(\mathrm{GH})$, pre-eclampsia $(\mathrm{PE})$ or eclampsia (E). All these hypertensive disorders affect approximately 5 to $10 \%$ of all pregnancies. In India, its incidence ranges from 5 to $15 \%$ (16\% in primigravidas and $7 \%$ in multigravidas). ${ }^{1}$

Globally, approximately 800 women die due to pregnancy-related complications every day. ${ }^{2}$ In India, roughly one maternal death occur every 5 minutes. ${ }^{3}$ Sixteen percent of all maternal deaths occur due to gestational hypertensive disorders. ${ }^{4}$ While in developing countries, of all pregnancy-induced hypertensive (PIH) disorders, majority of deaths result due to $\mathrm{E}$, in developed countries, complications of severe PE are more often the cause. $^{5}$

Pre-eclampsia is a multisystem disorder of unknown etiology and its development is influenced by both genetic and environmental risk factors. These risk factors include nulliparity, history of raised blood pressure (BP), pre-existing diabetes, multiple pregnancy and raised pre-pregnancy body mass index (BMI). ${ }^{6,7}$ In view of blood group as a risk factor for PE, it is suspected that PE may result from changes in vascular function, ${ }^{8}$ influenced by $\mathrm{ABO}$ blood group. $\mathrm{ABO}$ blood group, an easily accessible factor in a person's genetic make-up, may play a major role in interaction of immune and coagulation systems by influencing gene-environment interactions. There are different studies which support the association between $\mathrm{ABO}$ and $\mathrm{Rh}$ blood groups and PIH disorders. ${ }^{9,10}$ So, we undertook this study to find out if there is any relation between $\mathrm{ABO}$ system and PIH disorders among Indian population.

\section{MATERIALS AND METHODS}

This study was undertaken in Sri Ram Murti Smarak Institute of Medical Sciences, Bareilly, Uttar Pradesh, India, after taking approval from institutional Ethical Committee. We performed a retrospective analysis of 
patient records of all primigravidas admitted in our institution with diagnosis of PIH disorders during the period from Jan 2011 to Jan 2015. Patients were identified using census lists, hospital delivery records and pharmacy records in an effort to capture all primigravidas with singleton deliveries, categories of $\mathrm{PIH}, \mathrm{ABO}$ blood groups and $\mathrm{Rh}$ typing. Demographic information was recorded for each patient as well as obstetric course, i.e. time and route of delivery and treatment after delivery.

Thus, inclusion criterias were-primigravidas, singleton pregnancy, gestational hypertension or PE or $E$ and whether they needed treatment even after delivery or get subsided. Working group classification (NHBPEP, 2000) of hypertensive disorders complicating pregnancy was used for the evaluation of PIH disorders.

\section{Gestational Hypertension}

- Systolic $\mathrm{BP} \geq 140$ or diastolic $\mathrm{BP} \geq 90 \mathrm{~mm} \mathrm{Hg}$ for first time during pregnancy

- No proteinuria

- Blood pressure returns to normal before 12 weeks postpartum

- Final diagnosis made only postpartum

- May have other signs or symptoms of PE, e.g. epigastric discomfort or thrombocytopenia

\section{Pre-eclampsia}

Minimum criteria:

- Blood pressure $\geq 140 / 90$ mm Hg after 20 weeks' gestation

- Proteinuria $\geq 300 \mathrm{mg} / 24$ hours or $\geq 1$ and dipstick Increased certainty of PE:

- Blood pressure $\geq 160 / 110 \mathrm{~mm} \mathrm{Hg}$

- Proteinuria $2.0 \mathrm{gm} / 24$ hours or $\geq 2$ and dipstick

- Serum creatinine $>1.2 \mathrm{mg} / \mathrm{dl}$ unless known to be previously elevated

- Platelets < 100,000/ $\mu 1$

- Microangiopathic hemolysis- $\uparrow \mathrm{LDH}$

- Elevated serum transaminase levels-ALT/AST

- Persistent headache or other cerebral or visual disturbance

- Persistent epigastric pain

\section{Eclampsia}

- Seizures that cannot be attributed to other causes in a woman with PE.

Exclusion criteria's were-multiple pregnancy, primigravidas with other medical disease or condition likely to affect the pregnancy outcome, i.e. chronic hypertension, diabetes, renal or collagen vascular diseases, thyroid disorders, smoking or any drug use and any congenital fetal anomalies.

\section{STATISTICAL ANALYSIS}

The data were analyzed by using Microsoft Excel and Statistical Package of Social Sciences (SPSS). Categorical data analysis for comparison of percentages was performed with Chi-square contingency table analysis. Blood group $\mathrm{O}$ was taken as reference due to absence of both ' $\mathrm{A}$ ' and ' $\mathrm{B}$ ' antigens. The association of blood groups with different categories of PIH was estimated by calculating odds ratio from logistic regression models using blood group $\mathrm{O}$ as a reference. A ' $\mathrm{p}$ ' value of $<0.05$ was considered as statistically significant.

\section{RESULTS}

A total of 1964 primigravidas were identified during this period of which 324 were diagnosed with PIH. Of these, only 286 patients met the strict inclusion criteria and included for analysis as shown in Flow Chart 1. Among 286 primigravidas with PIH, 16 were Rh negative. Here, we found the prevalence of $\mathrm{PIH}$ in primigravidas was $14.56 \%$ of which $8.45 \%$ (166 cases) were diagnosed with gestational hypertension, $2.55 \%$ (50 cases) with PE and $3.56 \%$ (70 cases) with eclampsia. Among our study group, the major blood group was B (38.5\%) followed by $\mathrm{O}(26.6 \%)$, A (19.6\%) and AB (15.4\%), among which $94.4 \%$

Flow Chart 1: Study population

\begin{tabular}{|c|c|}
\hline $\begin{array}{l}\text { Total number of primigravidas } \\
\text { identified }(n=1964)\end{array}$ & $\begin{array}{l}\text { Excluded }(n=38) \\
\text {. Chronic hypertension }\end{array}$ \\
\hline$\downarrow$ & - Diabetes \\
\hline $\begin{array}{l}\text { Primigravidas diagnosed with } \\
\text { PIH }(n=324)\end{array}$ & $\begin{array}{l}\text { - Thyroid disorders } \\
\text { - Multiple pregnancy }\end{array}$ \\
\hline$\downarrow$ & - Collagen vascular diseases \\
\hline $\begin{array}{l}\text { Primigravidas with singleton } \\
\text { deliveries with } \mathrm{PIH}(\mathrm{n}=286)\end{array}$ & $\begin{array}{l}\text { - Smoking/drug use } \\
\text { - Congenital fetal anomalies }\end{array}$ \\
\hline
\end{tabular}

Table 1: Frequency distribution of primigravida women according to their different biosocial characteristics

\begin{tabular}{lll}
\hline Characteristic & Number & Percentage \\
\hline Age & & \\
$\geq 30$ years & 24 & 8.4 \\
$<30$ years & 262 & 91.6 \\
Weeks of & & \\
pregnancy & & \\
$\geq 37$ & 230 & 80.4 \\
$<37$ & 56 & 19.6 \\
Blood pressure & & \\
E & 70 & 24.5 \\
PE & 50 & 17.5 \\
GH & 166 & 58.0 \\
Blood group & & \\
A & 56 & 19.6 \\
AB & 44 & 15.4 \\
B & 110 & 38.5 \\
O & 76 & 26.6 \\
\hline
\end{tabular}




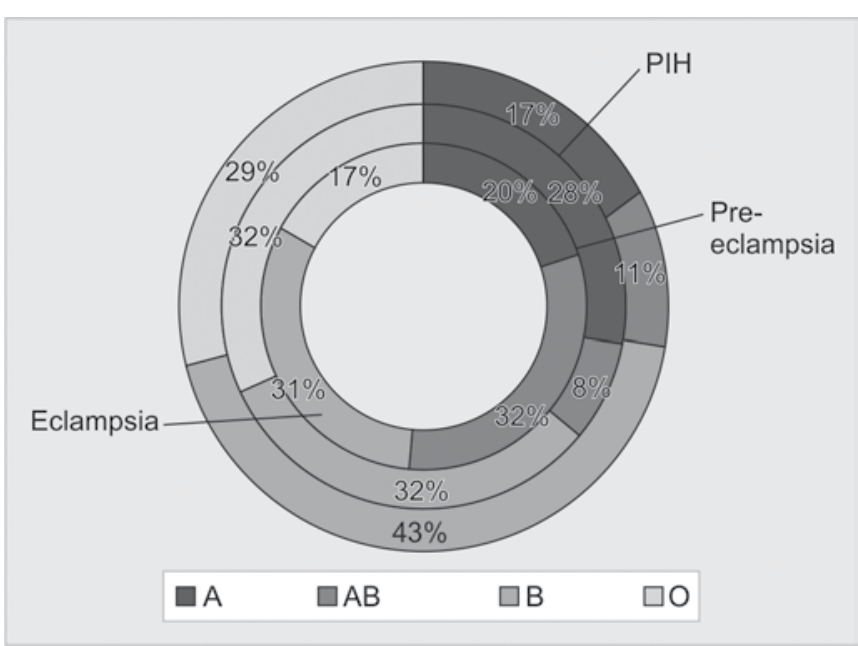

Graph 1: Frequency distribution of different categories of PIH among different blood groups

Table 2: Association of blood pressure with two different factors

\begin{tabular}{|c|c|c|c|c|}
\hline \multirow{2}{*}{$\begin{array}{l}\text { Variables } \\
\text { Weeks of pregnancy }\end{array}$} & \multicolumn{3}{|c|}{ Blood pressure } & \multirow[t]{2}{*}{ Chi-square ( $p$-value) } \\
\hline & $E$ & $P E$ & $\mathrm{GH}$ & \\
\hline$\geq 37$ & 48 & 40 & 142 & $9.012(0.011)$ \\
\hline$<37$ & 22 & 10 & 24 & \\
\hline \multicolumn{5}{|l|}{ Blood group } \\
\hline A & 14 & 14 & 28 & $8.180(0.017)$ \\
\hline$A B$ & 22 & 4 & 18 & \\
\hline$B$ & 22 & 16 & 72 & \\
\hline $\mathrm{O}$ & 12 & 16 & 48 & \\
\hline
\end{tabular}

were $\mathrm{RhD}$ positive. The mean age at delivery was 23.43 years with $\mathrm{SD}$ of 3.39 .

The characteristic distribution of women included in our study group are displayed in Table 1 . Most patients were less than 30 years of age $(91.6 \%)$ and at gestational age $\geq 37$ weeks $(80.4 \%)$ at the time of admission. Among different categories of PIH disorders, more than half were diagnosed with $\mathrm{GH}(58 \%)$. Blood group $\mathrm{B}$ was most common, whereas $\mathrm{AB}$ was least common and majority were of Rh positive blood group.

In Graph 1, frequency distribution of different categories of PIH among different blood groups can be seen.

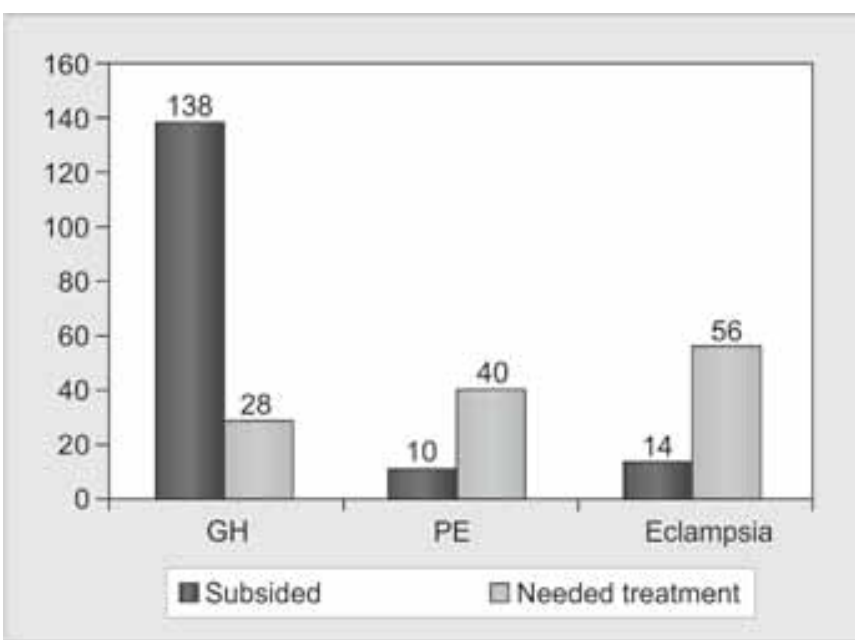

Graph 2: Comparison of patients who needed drugs for BP control $v s$ those whose raised BP subsided after delivery among different categories of $\mathrm{PIH}$

In Table 2, with the help of Chi-square test, it was observed that gestational age of pregnancy and blood groups have a significant association with PIH disorders. However, no association was found between Rh typing and PIH disorders.

In Table 3, taking blood group $\mathrm{O}$ as a reference, we found that blood group A has 50\% more risk of developing PE [OR = $1.500(0.638-3.528)]$. Blood group AB has five times highest risk of developing $\mathrm{E}[\mathrm{OR}=4.889$ (2.012-11.879)] as compared to O blood group. The trend of increasing odds ratio with severity of disease outcome was obvious for all non-O blood groups, i.e. $\mathrm{AB}, \mathrm{A}$ and $\mathrm{B}$.

In Graph 2, we can see that among majority of patients diagnosed with $\mathrm{GH}$, the raised BP was subsided after delivery, whereas in PE and E, most of the patients needed treatment even after delivery.

\section{DISCUSSION}

The results of our study indicate that primigravidas with $\mathrm{AB}$ blood group have highest risk of developing PIH disorders as compared to other blood groups. This finding is consistent with findings of Lee et al, ${ }^{9}$ Hiltunen et al ${ }_{10}^{10}$ Bharali et al, ${ }^{11}$ Phaloprakarn et al. ${ }^{12}$

Table 3: Odds ratio with $95 \%$ confidence interval $(\mathrm{Cl})$ based on multinomial regression models reflect the risk of $\mathrm{PE}$ and $\mathrm{E}$, compared to the reference group $\mathrm{GH}$

\begin{tabular}{lllll}
\hline & \multicolumn{4}{c}{ Blood pressure } \\
\cline { 2 - 5 } Independent Variables & PE $(95 \% \mathrm{Cl})$ & $p$-value & Eclampsia (95\%Cl) & $p$-value \\
\hline Weeks of pregnancy & & & & \\
Weeks of pregnancy $<37^{*}$ & 1.000 & - & 1.000 & - \\
Weeks of pregnancy $\geq 37$ & $0.676(0.299-1.530)$ & 0.348 & $0.369(0.190-0.717)$ & 0.003 \\
Blood groups & & & & - \\
O* & 1.000 & - & 1.000 & 0.132 \\
A & $1.500(0.638-3.528)$ & 0.353 & $2.000(0.812-4.924)$ & 0.000 \\
AB & $0.667(0.196-2.263)$ & 0.516 & $4.889(2.012-11.879)$ & 0.620 \\
B & $0.667(0.305-1.459)$ & 0.310 & $1.222(0.553-2.700)$ & \\
\hline
\end{tabular}


Of several hypothesis regarding association of blood groups with PIH disorders, one suggested mechanism is through maternal immune response. As per recent view on $\mathrm{PE}$, it is suggested that these patients have exaggregated maternal systemic immune response and characteristic changes in coagulation systems, differences in blood group may increase the risk of disease. A study concluded that placental protein 13 (PP13), an early biomarker of $\mathrm{PE}$, primarily produced by placenta has strongest affinity to blood group $\mathrm{AB}$. In women with $\mathrm{AB}$ blood group, the close proximity of $A$ and $B$ antigens can explain the stronger binding of PP13 to blood group $\mathrm{AB}$ erythrocytes leading to its sequestration. Thus, low level of 1st trimester maternal serum PP13 could predispose to PIH disorders. 13,14

In addition, compared with blood group $\mathrm{O}$, non-O (A, $\mathrm{B}, \mathrm{AB})$ blood groups are associated with an increased risk of thrombotic events, though this relationship is not confirmed. It may be due to the effect of von Willebrand factor (vWf), which was found higher in non-O (A, B, AB) blood group patients compared with blood group $\mathrm{O} .{ }^{15}$ Evidence suggests that vWf may promote platelet aggregation or adhesion and atherosis formation leading to endothelial dysfunction, a factor considered in pathogenesis of $\mathrm{PE}$. ${ }^{16,17}$ A variety of inflammatory markers associated with $\mathrm{PE}$, like tumor necrosis factor-alpha and soluble intercellular adhesion molecule 1 were found to be upregulated at $\mathrm{ABO}$ locus through polymorphism. According to a recent study, of diverse panel of inflammatory biomarkersE-selectin, P-selectin and ICAM- $1,{ }^{18}$ only E-selectin levels were found to be higher in PE cases vs controls. ${ }^{19}$

But, the role of blood groups in PIH cannot be concluded without a proper investigation of paternal blood group and its association. Another limitation of this study was as there is no water-tight compartment between different categories of PIH, some cases of mild $\mathrm{PE}$ that might have progressed to severe PE or E, no records of their progression could be make out. And being a retrospective study of patient records, we were not able to make out cases of severe PE or imminent $\mathrm{E}$, which is based more on clinical symptoms, and their association.

To summarize, though of modest sample size due to strict inclusion-exclusion criteria, our observations appear to have biological plausibility. The findings suggest an association between $\mathrm{ABO}$ blood groups and $\mathrm{PIH}$ in primigravidas among our population and support the hypothesis that genetic factors related to distribution of blood groups may play a role in development of hypertensive disorders of pregnancy. Hence, special attention should be given to primigravidas with $\mathrm{AB}$ blood group to prevent the complications of PIH and improve the prognosis. Although some strong risk factors for PE have been identified, the etio-pathogenesis is still poorly understood, and many recent research effort is being directed at investigating these biomarkers. ${ }^{20,21}$

\section{ACKNOWLEDGMENT}

We acknowledge Mr Vineet, Officer-in-Charge, Records Section, SRMS IMS, for continuous and timely support.

\section{REFERENCES}

1. Raddi SA, Nayak BS, Prakash R, Puri R, Metgud MC. Stress, Coping Strategies, Quality of Life and Lived Experiences of Women with PIH. J South Asian Federation of Obstet Gynaecol 2009;1(1):65-68.

2. World Health Organization Fact Sheet, May 2012.

3. Bakshi R. UNICEF unveils new tool to combat maternal mortality in India, UNICEF, Apr 6, 2006. Available at: http:// www.unicef.org/infobycountry/india_33208.html [Online].

4. Khan KS, Wojdyla D, Say L, Gulmezoglu AM, van Look PF. WHO analysis of causes of maternal death: a systematic review. Lancet 2006 Apr;367(1):1066-1074.

5. Turner JA. Diagnosis and management of preeclampsia: an update. Int J Women's Health 2010 Sep 30;2:327-337.

6. Duckitt K, Harrington D. Risk factors for pre-eclampsia at antenatal booking: systematic review of controlled studies. BMJ 2005;330:565.

7. Alpoim PNI, de Barros Pinheiro M, Junqueira DR, Freitas LG, das Gracas Carvalho M, Fernandes AP, et al. Preeclampsia and $\mathrm{ABO}$ blood groups: a systematic review and meta analysis. Mol Biol Rep 2013;40(3):2253-2261.

8. Roberts JM, Hubel CA. The two stage model of preeclampsia: variations on the theme. Placenta 2009;30(Suppl A):532-537.

9. Lee BK, Zhang Z, Wikman A, Lindqvist PG, Reilly M. $\mathrm{ABO}$ and $\mathrm{RhD}$ blood groups and gestational hypertensive disorders: a population-based cohort study. BJOG 2012; 119(10):1232-1237.

10. Hiltunen LM, Laivuori H, Rautanen A, Kaaja R, Kere J, Krusius T, et al. Blood group $\mathrm{AB}$ and factor $\mathrm{V}$ Leiden as risk factors for preeclampsia: a population-based nested casecontrol study. Thromb Res 2009 Jun;124(2):167-173.

11. Bharali R. ABO blood group-a risk factor for pregnancy induced hypertension. Int J Biol Med Res 2014;5(1):3797-3801.

12. Phaloprakarn C, Tangjitgamol S. Maternal ABO blood group and adverse pregnancy outcomes. J Perinatol 2013;33(2): 107-111.

13. Khalil A, Cowans NJ, Spencer K, Goichman S, Meiri H, Harrington K. First trimester maternal serum placental protein 13 for the prediction of pre-eclampsia in women with a priori high risk. Prenat Diagn 2009;29(8):781-789.

14. Gonen R, Shahar R, Grimpel YI, Chefetz I, Sammar M, Meiri $\mathrm{H}$, et al. Placental protein 13 as an early marker for pre-eclampsia: a prospective longitudinal study. BJOG 2008; 115(12):1465-1472.

15. Sun C, Chen Y, Zhang W, Yu S. Association between von Willebrand factor gene polymorphism and preeclampsia: J Perinatal Medicine 2008;37(1):36-42.

16. Parra-Cordero M, Bosco C, González J, Gutiérrez R, Barja $\mathrm{P}$, Rodrigo R. Immunohistochemical expression of von Willebrand factor in the preeclamptic placenta. J Mol Histol 2011 Oct;42(5):459-465. 
17. Nadir SK, Al Yemini E, Blann AD, Lip GY. Thrombomodulin, von Willebrand factor and E-selectin as plasma markers of endothelial damage/dysfunction and activation in pregnancy induced hypertension. Thromb Res 2004;113(2):123-128.

18. Barbalic M, Dupuis J, Dehghan A, Bis JC, Hoogeveen RC, Schnabel RB, et al. Large-scale genomic studies reveal central role of ABO in sP-selectin and sICAM-1 levels. Hum Mol Genet 2010;19(9):1863-1872.

19. Carty DM, Anderson LA, Freeman DJ, Welsh PI, Brennand JE, Dominiczak AF, et al. Early pregnancy soluble E-selectin concentrations and risk of preeclampsia. J Hypertens 2012 May;30(5):954-959.
20. Erez O, Romero R, Espinoza J, Fu W, Todem D, Kusanovic JP, et al. The changes in concentrations of angiogenic and antiangiogenic factors in maternal plasma between the first and second trimesters in risk assessment for the subsequent development of preeclampsia and small-for-gestational age. J Matern Fetal Neonatal Med 2008 May;21(5):279-287.

21. Chedraui P, Lockwood CJ, Schatz F, Buchwalder LF, Schwager G, Guerrero C, Escobar GS, Hidalgo L. Increased plasma soluble fms-like tyrosine kinase 1 and endoglin levels in pregnancies complicated with preeclampsia. J Matern Fetal Neonatal Med 2009 Jul;22(7):565-570. 